\title{
Corrosion behavior of Tinplate in Aerated and Deaerated $\mathrm{NaCl}$ Solution
}

\author{
Dejing Zhou ${ }^{1,2}$, Jihui Wang ${ }^{2, *}$, Zhewen Han ${ }^{2}$, Xin Liu' ${ }^{2}$,Jing Mao ${ }^{2}$ \\ ${ }^{1}$ Jiangsu Key Laboratory for Clad Materials, Wuxi Yinbang Clad Material Co., Ltd, Wuxi 21400, P. \\ R. China \\ ${ }^{2}$ Tianjin Key Laboratory of Composite and Functional Materials, School of Materials Science and \\ Engineering, Tianjin University, Tianjin 300072, P. R. China \\ *E-mail: jhwang@tju.edu.cn
}

doi: $10.20964 / 2017.01 .23$

Received: 17 September 2016 / Accepted: 5 November 2016 / Published: 12 December 2016

The corrosion behavior of tinplate in aerated and deaerated sodium chloride solution was investigated by using polarization curve, electrochemical impedance spectroscopy (EIS) and immersion tests. The corroded surface of tinplate was characterized by scanning electron microscopy (SEM) and X-ray photoelectron spectroscopy (XPS) techniques, and the concentration of iron and tin ions dissolved in solution was determined by inductively coupled plasma mass spectrometer (ICP-MS). In aerated solution, tinplate has a higher corrosion current density and two time constants in EIS spectrum. The concentration of iron ions in solution is increased with immersion time, but the concentration of tin ions keeps almost unchanged. In deaerated solution, tinplate has a lower corrosion current density and one time constant in EIS spectrum. The concentration of iron and tin ions in solution is increased with the immersion time, but the concentration of tin ions is larger than that of iron ion. The corrosion process of tinplate in aerated solution is predominated by the dissolution of steel substrate, whereas in the deaerated solution the corrosion of tinplate is mainly by the dissolution of tin coating.

Keywords: Tinplate; corrosion; sodium chloride solution; deaerated condition

\section{$\underline{\text { FULL TEXT }}$}

(C) 2017 The Authors. Published by ESG (www.electrochemsci.org). This article is an open access article distributed under the terms and conditions of the Creative Commons Attribution license (http://creativecommons.org/licenses/by/4.0/). 